\title{
UNDERWATER ACOUSTIC CHANNEL MODELING PROPOSAL FOR SHALLOW WATER COMMUNICATION LINK OPTIMIZATION
}

\author{
Marcus Vinícius da Silva Simões ${ }^{1}$, Carlos Eduardo Parente Ribeiro² and Luiz Gallisa Guimarães²
}

\begin{abstract}
Since 80's, underwater acoustic digital communication has being one of the principal topic in underwater acoustics research. Besides, underwater waveguide modeling also has been a subject of intensive research taking benefit of the increase in available computational power and data volume provided by the new generation of ocean data measurements instruments. In shallow water specific scenario, normal-mode acoustic propagation models are still based on classic Pekeris two layers ocean model. Our paper also starts from Pekeris but uses some different approaches based on waveguide coupling and in generalized adiabatic coupled mode theory. In other words, we used the property that all waveguides could be acoustically excited by transmission resonance of consecutive modes, considering an adiabatic invariant channel. Trying to validate the model, synthetic results are compared with transmission loss measurements in field experiment.
\end{abstract}

Keywords: waveguide, adiabatic, couple modes, resonance.

RESUMO. Desde a década de 80, a comunicação digital tem sido um dos principais tópicos nos estudos de acústica subaquática. Além disso, a modelagem do guia de ondas submarino também tem sido objeto de pesquisa intensa aproveitando-se do aumento do poder computacional disponível e do volume de dados fornecido pela nova geração de instrumentos de coleta de dados oceânicos. Em um cenário específico para águas rasas, os modelos de propagação acústica de modo normal ainda têm como base o modelo clássico de oceano em duas camadas de Pekeris. Nosso artigo também começa a partir de Pekeris mas usando algumas abordagens diferentes, baseadas no acoplamento de guias de ondas e na teoria de modos adiabáticos acoplados. Em outras palavras, usamos a propriedade em que os guias de ondas podem ser acusticamente excitados por transmissão ressonante de modos consecutivos, considerando um canal adiabático invariante. Buscando a validação do modelo, os resultados sintéticos são comparados com medidas de perda de transmissão em um experimento de campo.

Palavras-chave: guia de ondas, adiabático, modos acoplados, ressonância.

\footnotetext{
${ }_{1}^{1}$ Marinha do Brasil, Instituto de Estudos do Mar Almirante Paulo Moreira - IEAPM - Departamento de Acústica Submarina - Rua Kioto 253, Praia do Anjos, Arraial do Cabo, Rio de Janeiro - E-mails: mvssimoes@gmail.com, marcus.simoes@marinha.mil.br

${ }^{2}$ Universidade Federal do Rio de Janeiro - UFRJ, Programa de Pós-graduação em Engenharia Oceânica - PENO, LIOc - Laboratório de Instrumentação Oceanográfica - E-mails: parente@peno.coppe.ufrj.br, lula@if.ufrj.br
} 


\section{INTRODUCTION}

In deep water it is well known that vertical temperature variation behavior is a major single factor determining the transmission of sound of a given frequency. Sea surface roughness constitutes a second factor, and other oceanographic variables are poorly quantified on sound transmission (Urick, 1983).

In shallow water, the number of factors affecting sound transmission increases conceivably. Considering that in shallow water not only the vertical temperature of the ocean is the preponderant parameter as in deep water, Bergmann et al. (1969) on Part 1 Chapter 6 states that "...it would be impractical to make a large number of sound transmission runs and then obtain rules of sound propagation empirically merely by subjecting the data amassed to and unprejudiced statistical analysis. Rather, it was found necessary to assess beforehand the possible effects of bottom character, roughness of the sea surface, and refraction conditions, and then to analyze the transmission run data purposefully". Nowadays, not only computational analysis, data assimilation and modeling but also new oceanographic and geological instruments for in situ measurements keep the same approach valid with the obvious advantage of speed processing and data amount collected.

The main goal of this paper is to model part of the problem, studying the waveguide energy transmission behavior using modal propagation under certain boundary conditions to analyze qualitatively energy flux along of the water column at certain range from the source. This approach could be useful to suggest a methodology for 3D topology fix node network implementation (latitude and longitude node position and optimized depth for the transducers) on a underwater acoustic communication network (UAN) in shallow waters.

The synthetic results were confronted with the RASCOMM'14 sea trial transmission loss computation results obtained among pre-chosen network node spots, proposed for the UAN 2D topology with fixed depth hydrophone position.

\section{METHODOLOGY}

\section{Theoretical Approach for proposed propagation model development}

In this work we assume the following premises: harmonic field propagation ( $e^{-i \omega t}$, with $\omega=2 \pi f$ ), azimuthal symmetry, a temporal frequency $f$ and adopted the cylindrical coordinated system $(r, z)$.

Under these assumptions, for a punctual source located at depth $z=z_{s}$ the Helmholtz equation related to the sound pressure behavior $p$ in range $r$ as well as in depth $z$ could be written as proposed in Jensen et al. (2011)

$$
\begin{gathered}
\frac{1}{r} \frac{\partial}{\partial r}\left(r \frac{\partial p}{\partial r}\right)+ \\
+\rho(z) \frac{\partial}{\partial z}\left(\frac{1}{\rho(z)} \frac{\partial p}{\partial z}\right)+ \\
+\frac{\omega^{2}}{c^{2}(z)} p=\frac{-\delta\left(z-z_{s}\right) \delta(r)}{2 \pi r} .
\end{gathered}
$$

Considering the wave propagation point of view, it is suitable to describe the present waveguide as the superposition of two distinct layers and an infinite seabed set up as in Figure 1. More specifically, mixture and thermocline layers are characterized by density and sound velocity profile $\rho_{0}, c_{0}$ and $\rho_{1}, c_{1}$ respectively, while in the seabed we have $\rho_{2}, c_{2}$. Besides, we define the local depth as $H$ and the effective thermocline waveguide depth as $h=H-z_{M}$ respectively and $z_{M}$ as the final depth of the mixture layer.

Applying the separable variable method such that $p(r, z)=$ $\Psi(z) H_{0}^{1}(r)$, where $H_{0}^{1}$ is the zero order outgoing Hankel function as in Jensen et al.(2011) assuming that depth pressure behavior wave function $\Psi(z)$ should satisfies:

$$
\Psi(z)=\left\{\begin{array}{l}
f_{0}=A_{0} \sinh \left(q_{0} z\right) ; z>0 \text { and } z \leq z_{M} \\
f_{1}=A 1 \sin \left(k_{1}\left(z-\frac{\left(z_{M}+H\right)}{2}\right)+\right. \\
+B 1 \cos \left(k_{1}\left(z-\frac{\left(z_{M}+H\right)}{2}\right)\right) \\
z>z_{M} \text { and } z \leq H \\
f_{2}=A_{2} e^{-q_{2}(z-H)} ; z>H .
\end{array}\right.
$$

Where the constants $A_{0}, A_{1}, B_{1}$ and $A_{2}$ are determined by problem boundary conditions as well as by the wave function $\Psi$ orthogonality criteria as in Jensen et al. (2011).

In addition, we assume that the stratified fluid density $\rho(z)$ behaves in depth as:

$$
\rho(z)=\left\{\begin{array}{l}
\rho_{0} ; z>0 \text { and } z \leq z_{M} \\
\rho_{1} ; z>z_{M} \text { and } z \leq H \\
\rho_{2} ; z>H .
\end{array}\right.
$$

Besides, here we adopted $c_{2}>c_{0}>c_{1}$ and for a given radial wavenumber $k_{r}$, we define for the $j$-th layer the depth wave propagation $k_{j}$ and penetration $q_{j}$ numbers respectively as:

$$
\begin{aligned}
& k_{j}\left(k_{r}\right)=\sqrt{\frac{\omega^{2}}{c_{j}^{2}}-k_{r}^{2}}, \\
& q_{j}\left(k_{r}\right)=\sqrt{k_{r}{ }^{2}-\frac{\omega^{2}}{c_{r}{ }^{2}}}
\end{aligned}
$$




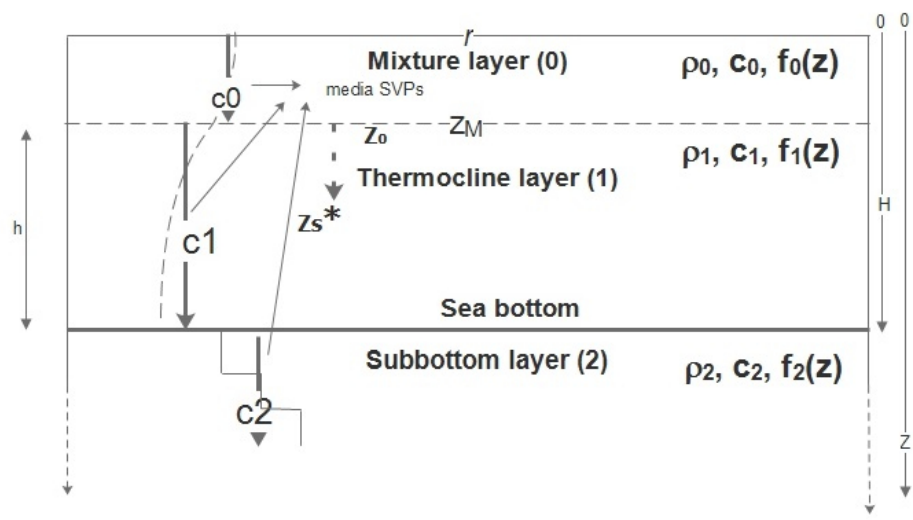

Figure 1 - The Double Layer Pekeris Waveguide (DLPW).



Figure 2 - Possible modes in three distinct DLPW.
In order to satisfy the acoustic problem boundary conditions, it is necessary to impose the conservation of pressure as well as the continuity of normal component to surface of particle velocity at each interface between layers as in Frisk (1994)and Jensen et al. (2011). Under these assumptions, an approximated far field problem modal solution is given by the following residue series (Jensen et al., 2011),

$$
p(r, z) \approx \frac{i p_{0}}{\rho\left(z_{s}\right) \sqrt{8 \pi r}} e^{\frac{-i \pi}{4}} \sum_{n=1}^{\infty} Z_{n}\left(z_{s}\right) Z_{n}(z) \frac{e^{i k_{n} r}}{\sqrt{k_{n}}}
$$

Where $p_{0}$ is the value of the reference pressure close to the source located at the depth $z_{s}$ and the integers $n=1,2, \ldots$ are the normal mode number related to discrete $k_{r} \mapsto k_{r, n}$ radial wavenumber $k_{r ; n}$ and wavelength $\lambda_{r ; n}$ such that $k_{r ; n}=2 \pi / \lambda_{r ; n}$, which are the $n$-th solution of the transcendental equation $\Delta$ given by the following determinant Eq.(7). For frequencies and local depths around few $\mathrm{kHz}$ and some meters respectively Figure 2 sketches for three distinct DLPW the typical behavior of allowed propagating modes for three different local depths $H_{1}<H_{3}<$ $\mathrm{H}_{2}$ respectively.

$$
\Delta=\left|\begin{array}{cccc}
\rho_{0} \sinh \left(q_{0} z_{M}\right) & -\rho_{1} \sin \left(1 / 2 k_{1}\left(z_{M}-H\right)\right) & -\rho_{1} \cos \left(1 / 2 k_{1}\left(z_{M}-H\right)\right) & 0 \\
\cosh \left(q_{0} z_{M}\right) q_{0} & -\cos \left(1 / 2 k_{1}\left(z_{M}-H\right)\right) k_{1} & \sin \left(1 / 2 k_{1}\left(z_{M}-H\right)\right) k_{1} & 0 \\
0 & -\rho_{1} \sin \left(1 / 2 k_{1}\left(z_{M}-H\right)\right) & \rho_{1} \cos \left(1 / 2 k_{1}\left(z_{M}-H\right)\right) & -\rho_{2} \\
0 & \cos \left(1 / 2 k_{1}\left(z_{M}-H\right)\right) k_{1} & \sin \left(1 / 2 k_{1}\left(z_{M}-H\right)\right) k_{1} & q_{2}
\end{array}\right|
$$

In general, in underwater acoustic problems, it is common to measure sound scales in $\mathrm{dB}$ (Fig. 3). Considering that the Transmission Loss (TL) in the waveguide is given by:

$$
T L(r, z)=-20 \log \left|\frac{p(r, z)}{p_{0}}\right| .
$$

Furthermore, it is possible to relate some $\lambda_{r, n}$ to $\mathrm{a}$ distinct modal number value $n_{j}$, in other words, the phases of distinct modal waves can radially constructively interfere each other if the related wavelengths are similar (Fig. 4). Moreover, this constructive interference process can be improved if the separation between consecutive nodes of distinct vertical modal wave functions $\Psi_{n_{j}}$ are similar too (Fig. 5). When these radial and vertical modal phases simultaneously match, the conditions to excitation of Adiabatic Transmission Resonance - ATR wave propagation is fulfilled. We show along this paper that ATR has a fundamental role in the physical mechanism related to acoustic energy propagation in real underwater waveguides. In the following sections, we will detail our numerical and experiment results. 


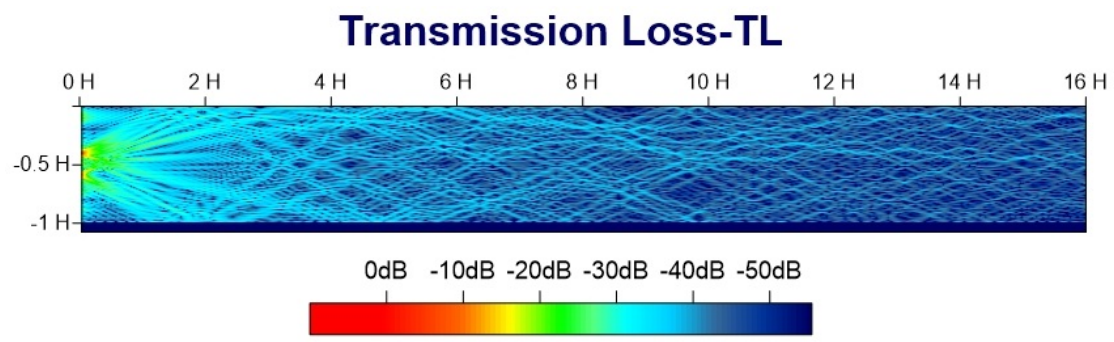

Figure 3 - Transmission Loss with source on half-way position on depth $(\mathrm{H})$

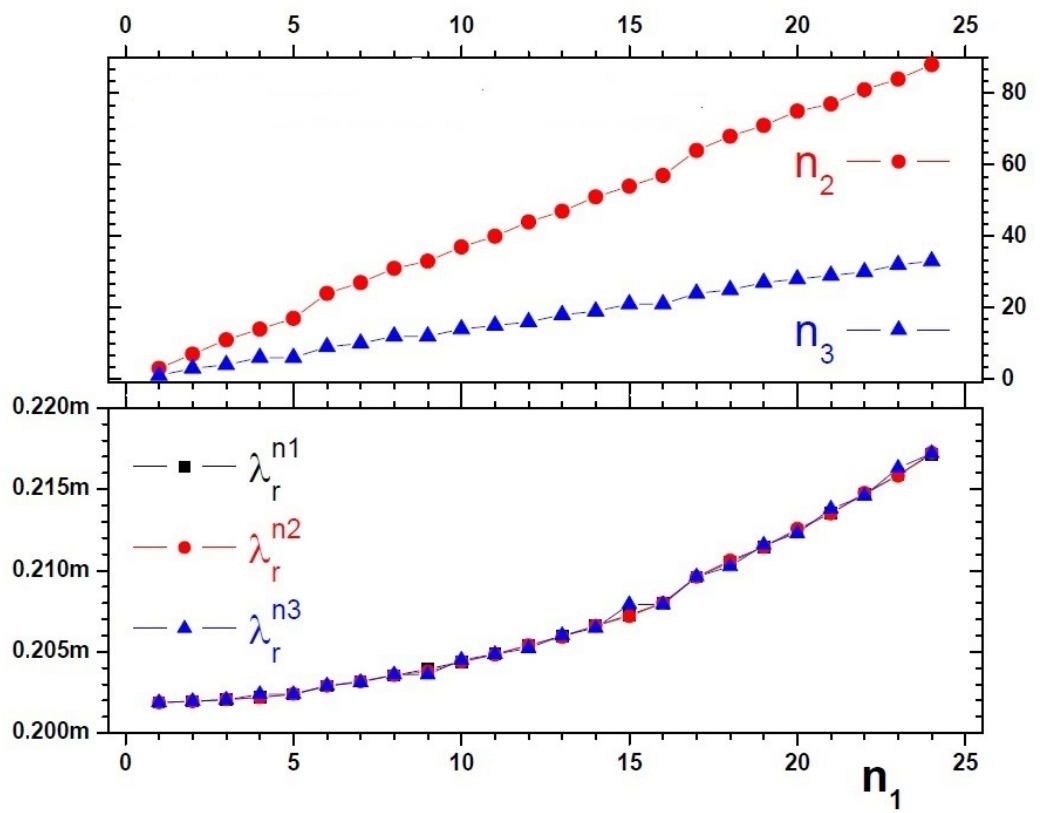

Figure 4 - Radial Phase Matching.

\section{Collecting data: The RASComm'14 experiment}

The experiment objective was to collect data for transmission loss (TL) computation in a specific topology with a preset hydrophone and source geometry. All major parameters that influence on the waveguide (ocean) variability were measured. Some parameters like currents and subbottom composition even taking part on attenuation of the signal, and consequently on TL computation, were released due to its secondary role on qualitative results for proposed model validation.

\section{Source, Receiver and Signals}

The experiment uses a 10 min ( 5 min LFM (CHIRP) and 5 min CW (Tone)) transmission period with one second LFM signals from 5 $\mathrm{kHz}$ to $10 \mathrm{kHz}$ with same silence interval and a 1 second tone at frequencies $5,5.5,6.0 \ldots 10 \mathrm{kHz}$ with one second interval starting and ending with same silence period. Only the LFM signals were used for TL computation. Unfortunately, due to operational problems during ship positioning not only both vessels ( $\mathrm{AvPq}$ Aspirante Moura (U14) and AvPq Diadorim (IEAPM-01) but also receiving (RX at P5) and transmission stations ( $T X$ at $P 1$, P2, P3 and P4) (Fig. 9) were set in non-ideal depths. The source was lowered at $10 \mathrm{~m}$ from midship (middle) with double anchorage scheme (bow (front) and stern (rear)), to provide alignment with local wind to avoid rotation and keeping midship and source front direct pointed to P5. The source deployment was made using bow and stern fixed point onboard (inside) IEAPM01 to guarantee midship position and $10 \mathrm{~m}$ depth for transmission. All this configuration was necessary to minimize positions and movement errors due to the absent of attitude sensor for TX and RX configuration. At the receiver site U14 anchored at $25 \mathrm{~m}$ bottom (expected hydrophone position at 


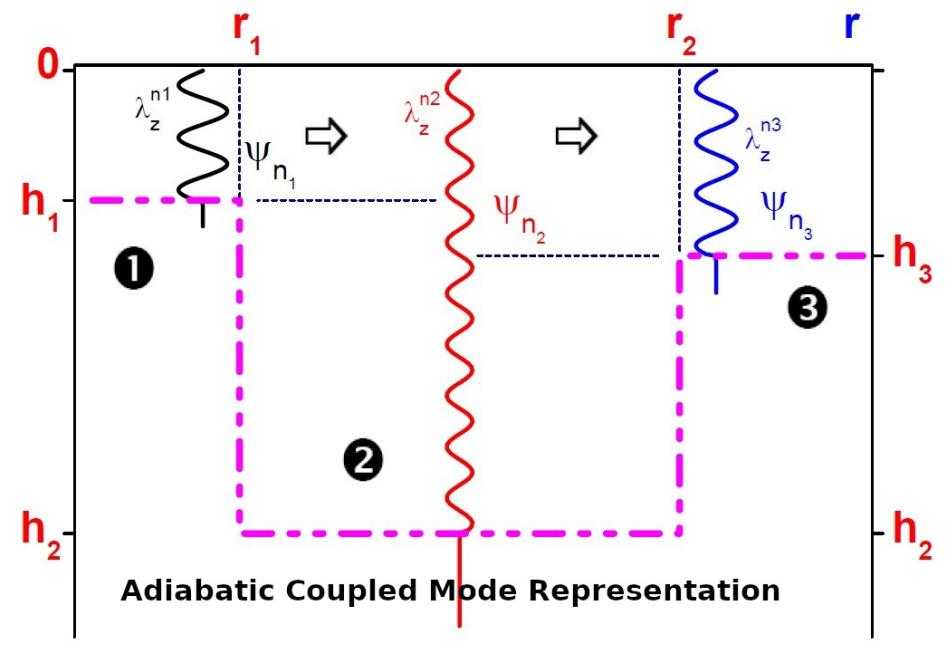

$\mathbf{z}$

Figure 5 - Adiabatic Nodes Coupling.

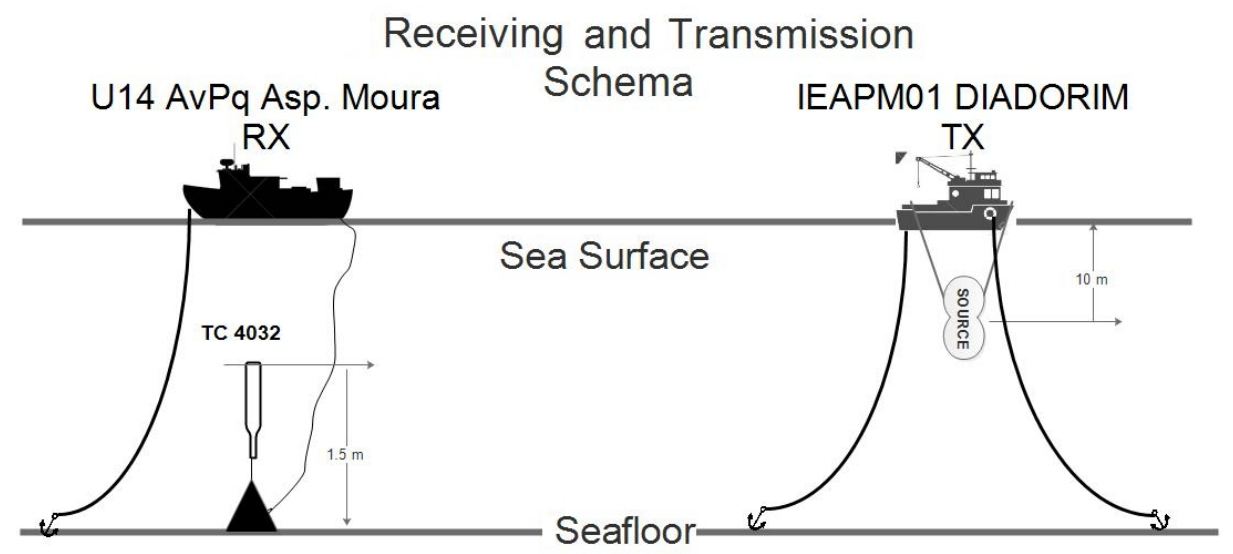

Figure 6 - Receiving and Transmission Scheme of RASComm'14 experiment.

-23 m) abeam positioned to IEAPM01 to allow a direct bearing to all transmission points. This ship alignment also allowed the smallest variation on position due to swell, wind direction change and ship wave movements (Fig. 6).

The transmission was made with a linear array of three sources tonpilz type model EDO 610 E with a transmission voltage response (TVR) measured in lab as shown in Figure 7. The applied voltage was $960 \mathrm{v}$ to obtain around $280 \mathrm{~dB}$ of sound pressure level (SPL - re 1v per $\mu \mathrm{Pa}$ ) positioned at a $10 \mathrm{~m}$ depth facing toward the receiving station.
At receiving point (P5) we set up two hydrophones, one RESON TC4032 with $10 \mathrm{~dB}$ preamplifier differential connection and $5 \mathrm{~Hz}$ do $120 \mathrm{kHz}$ receiving band (Fig. 8) and a PI hydrophone without preamplifier and unknown specifications ${ }^{1}$ in same receiving position (2.0 $\mathrm{m}$ above seafloor), see Figure 6 . The used transmission set up (stationary source around $10 \mathrm{~m}$ ) did not avoid influence of ship movement and currents (tidal inflow and outflow were observed but not measured at the experiment site), which insert some Doppler spread on the signal but with minimum influence on TL computation. Unfortunately, the

\footnotetext{
${ }^{1}$ This equipment worked fine on lab tests, but were not calibrated for the experiment. It was used to double check if the transmitting signal has enough sound pressure level (SPL) to sensitize a non-amplified hydrophone.
} 


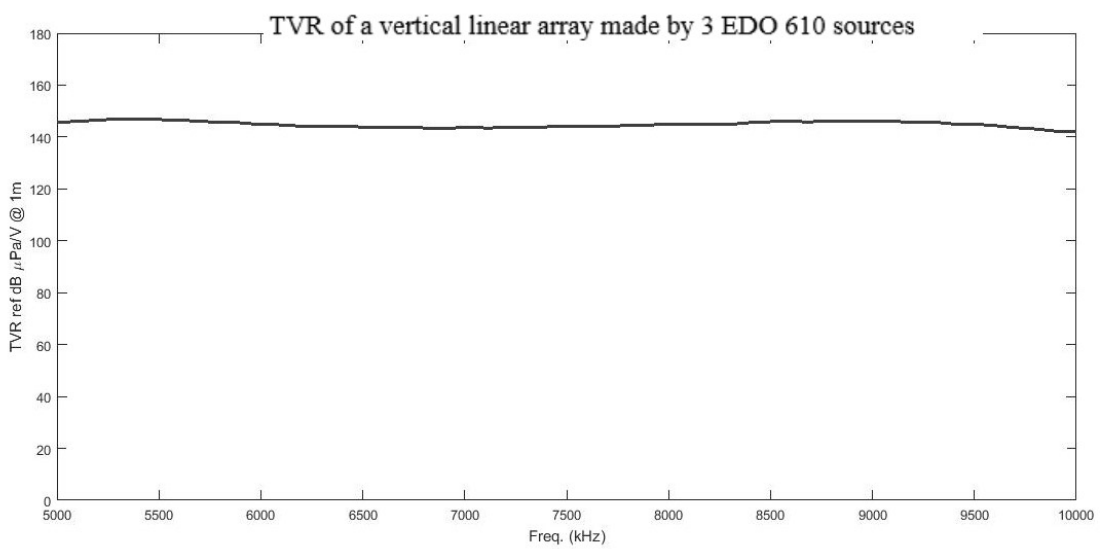

Figure 7 - TVR of vertical linear array with 3 sources type ED0 610.

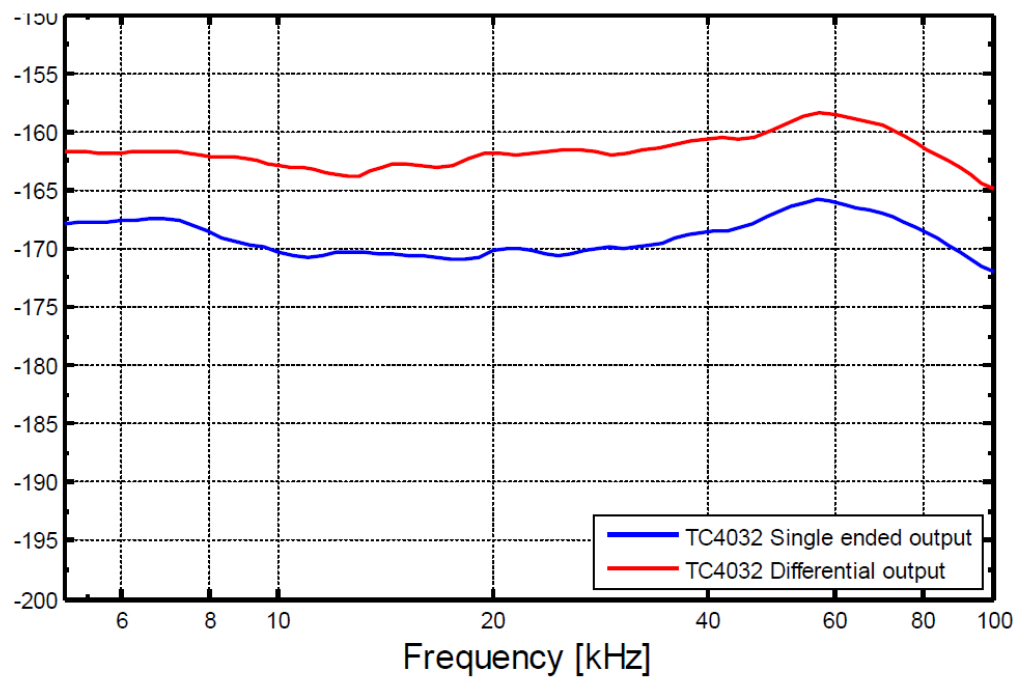

Figure 8 - OCRR (sensibility) of RESON TC4032.

accurate active array hydrophone positioning was not possible due to a lack of sensors as mentioned above.

\section{Network topology, waveguide geometry and parameters}

\section{Topology}

The nodes network positions were chosen with three main future objectives: first to capture all vessels traffic (anthropogenic noise) of Arraial do Cabo port; second to capture biological noise of secondary coves in the region (Anjos, Forno and Carneiro) and Porcos Island and North part of Cabo Frio Island (CFI); and third, node in shallow water with easy access in a depth that could be easily reached by divers (for maintenance purposes). This choice of set up for topology of the future communication and sensing network demands that the peer to peer links among node must be on all time allowing the best rate of transmission as long as possible (Fig. 9).

\section{Waveguide}

To measure the waveguide (or the channel) robustness to sustain communication we choose to measure the transmission loss ( $\mathrm{TL}$ ) parameter at different frequencies using the largest band that our equipment allowed. To do it we set four transmission points (TX) aiming a three sources linear array to a receiving position (RX) 


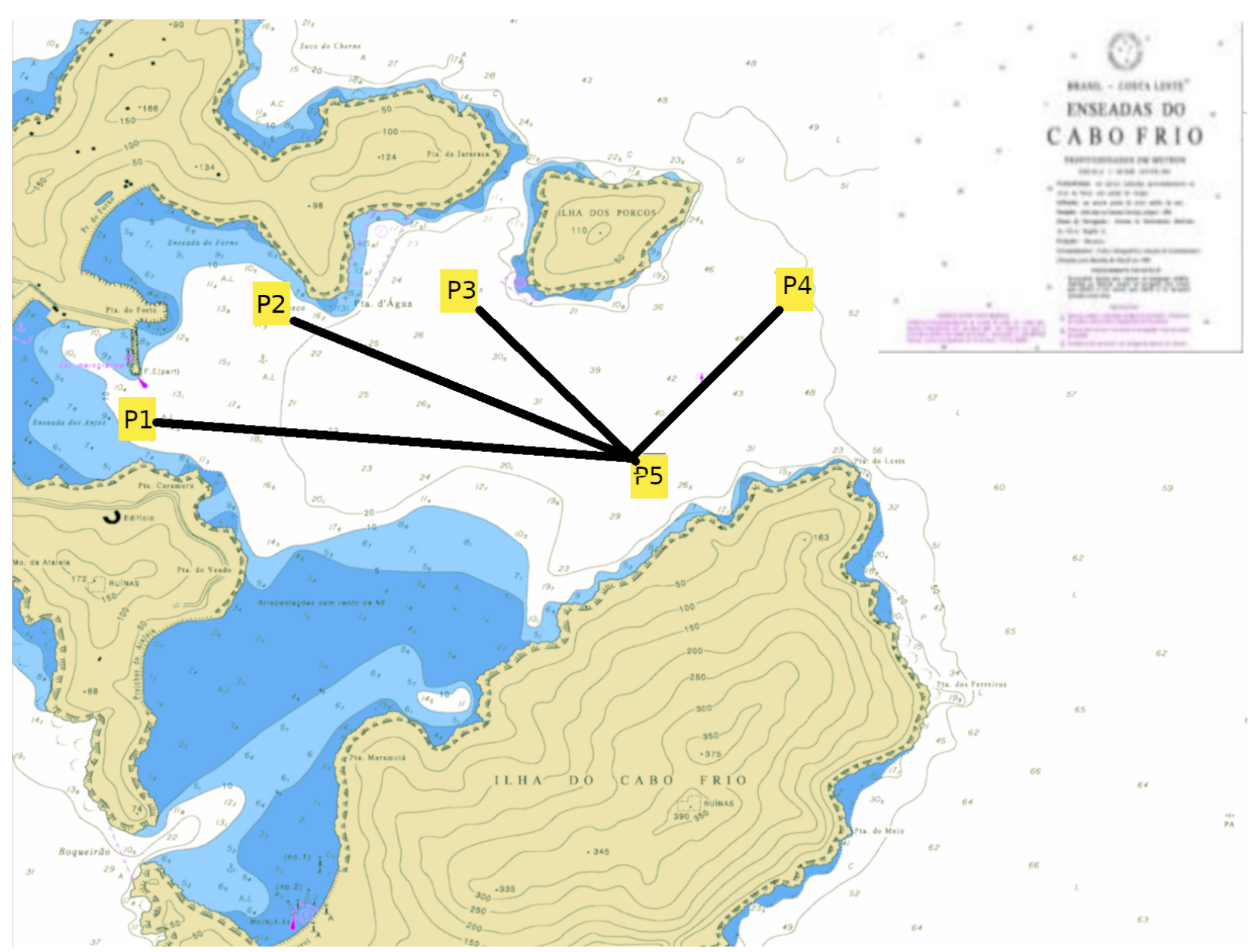

Figure 9 - UAN proposed topology for Arraial do Cabo's coves (subset of DHN 1503 Nautical Chart).

in four different bathymetric bearings among transmission points (P1, P2, P3 and P4) and a fixed receiving point (P5) Figure 9. Figures 10 and 11 show P1-P5 and P4-P5 profiles, respectively.

\section{Winds and upwelling condition}

Waveguide conditions were typical of fall upwelling period (Torres Junior, 1995; Elias, 2009) with winds blowing from $E$ and NE direction with peaks of $11 \mathrm{~m} / \mathrm{s}$ and at least three days persistence as show in Figure 12. This condition allowed upwelling development which get in Arraial's Coves from two main entrances: first from Boqueirão (mouth between continent and SW part of CFI) increased by tidal influx and secondly from the cove region main entrance between East point of CFI and Porcos' Island (small island between point P4 and P3 on Fig. 9) with a secondary influx from small mouth between Jararaca's point and Porcos' Island. Most measurements were made during tidal influx which facilitated subsurface upwelling insertion confirmed by CTD (Conductivity, Temperature and Depth) profilers, with Sound Velocity Profile (SVP) computed (Wilson, 1960) and direct SVP profilers on RX position P5 (Fig. 13 ).

\section{Bathymetry}

Bathymetry was obtained from a series of multibeam and singlebeam hydrographic surveys (Fig. 14) which allowed a quite precise bathymetric profile between $T X$ and RX points as show in Figures 10 and 11 used to compute mean depth for waveguide model use on TL computation.

\section{Seafloor, currents, subbottom and sea surface}

Seafloor is characterized by fine mobile sand (Silva, 2009) that changes place from time to time due to wind regime, tidal generated bottom currents and extreme wave events, mainly on the shallow sand bank between $\mathrm{CFI}$ and the continent (dark blue 


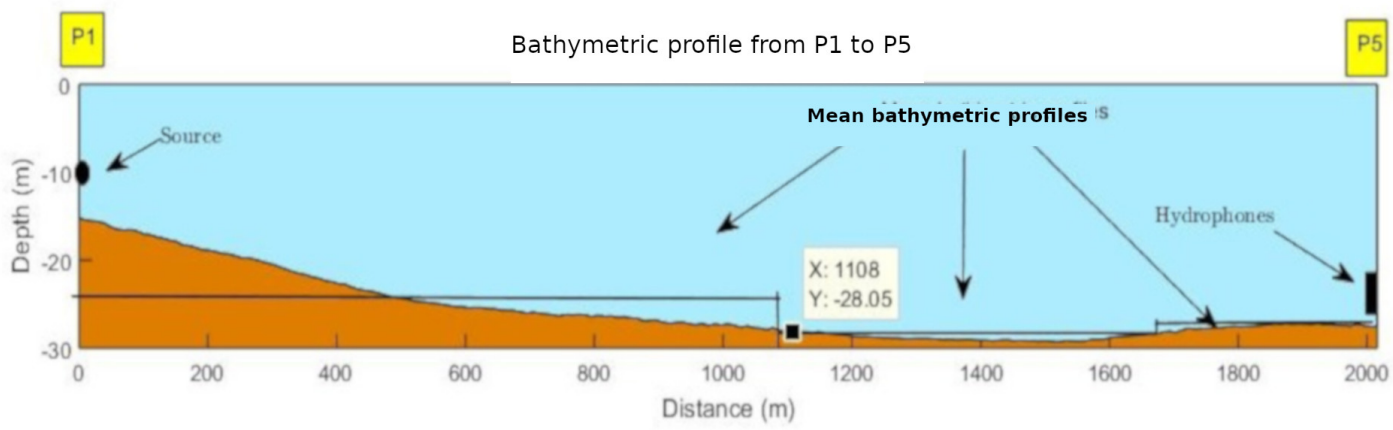

Figure 10 - Bathymetric profile heading from P1 and P4 (TX) to P5 (RX).

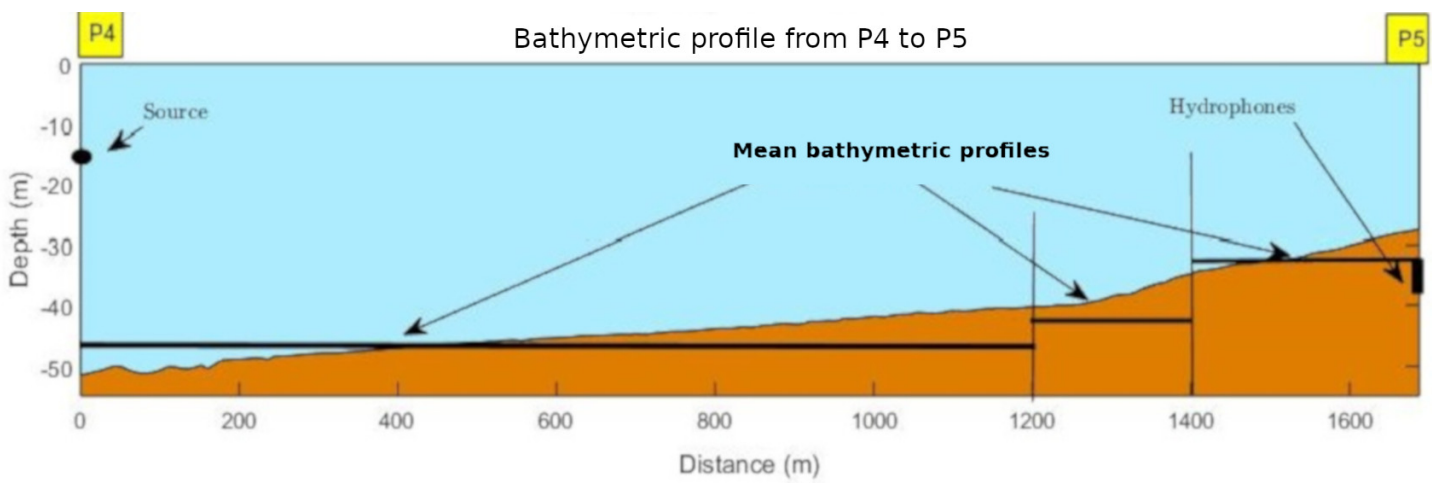

Figure 11 - Bathymetric profile heading from P4 (TX) to P5 (RX).
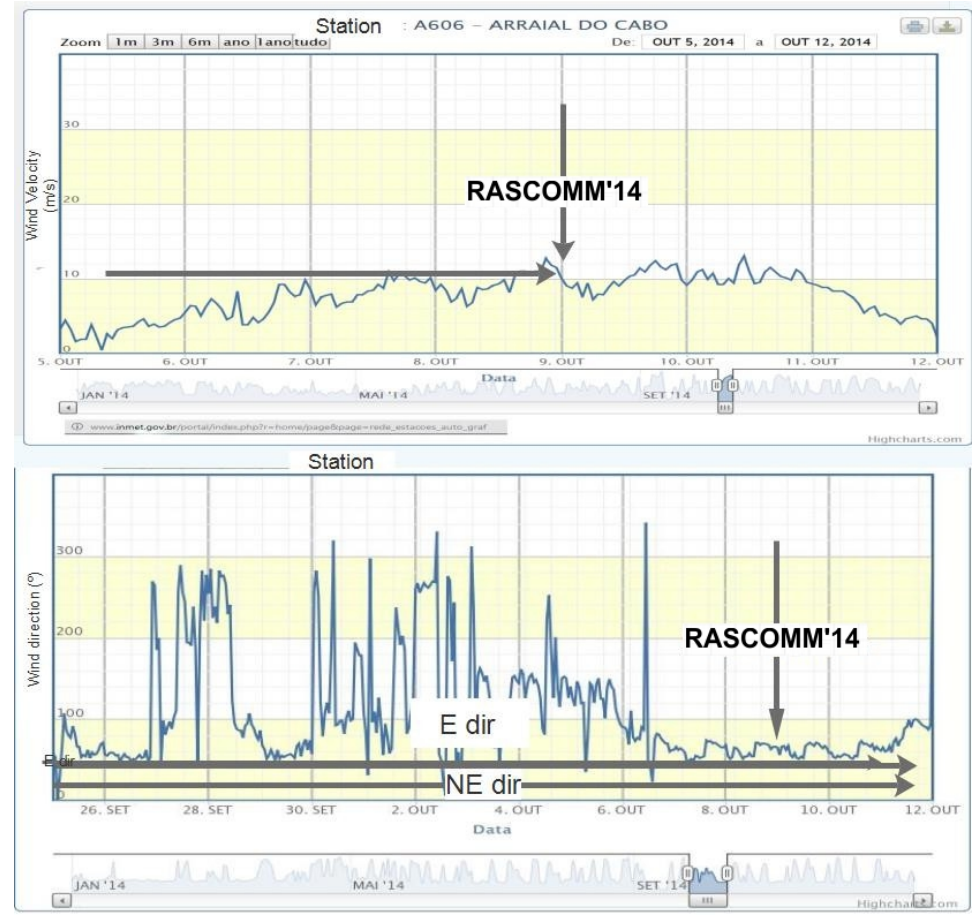

Figure 12 - Wind regime (direction and velocity) on site during the trail RASCOMM'14. 

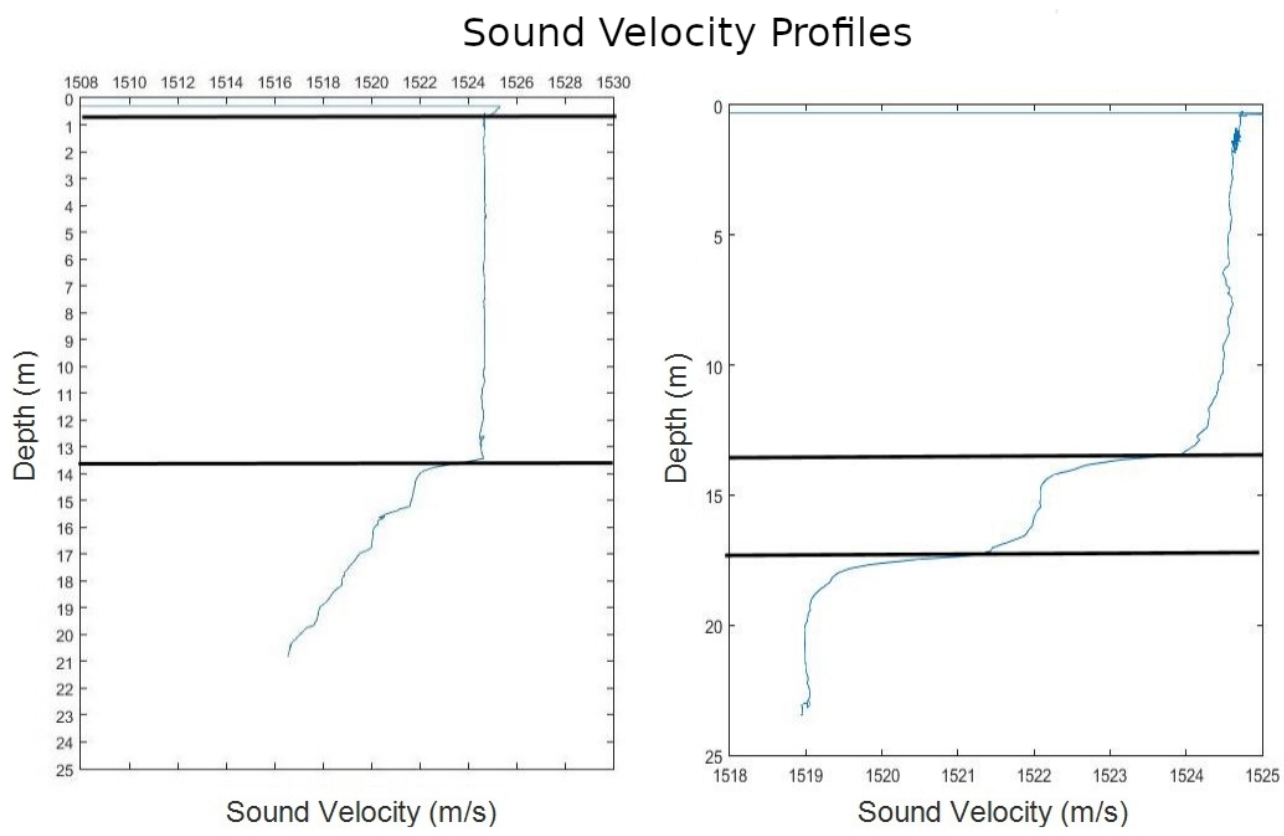

Figure 13 - SVP on P5 during P25 and P45 transmission.

on the nautical chart 1503 - Fig. 9) with minor changes in grain diameter inside the inner region (Silva, 2009).

The absence of current measurements did not affect the results since the Doppler effect has a minimum influence in TL computation due to the position of the nodes are fixed. The influence of the source and receiver movements are also considered negligible.

Taking into account that the proposed model was designed to compute mode propagation that have almost non-interference with seabed and sea surface, the measurements of seabed properties and sea surface, movement were considered outside the scope of this paper.

\section{MODEL VALIDATION: SYNTHETIC VERSUS REAL DATA}

\section{Computing real data transmission loss}

\section{Signal Processing}

All receiver signals collected were processed to obtain the $\mathrm{TL}$ values for all LFM signals received. Total signal has 320 seconds (16Mi samples) using a sample rate of $50 \mathrm{~K}$ samples/s of $1 \mathrm{~s}$ LFM from 5 to $10 \mathrm{kHz}$ and 1s silence that were cut in 20s signal bundles. The 5 to $10 \mathrm{kHz}$ signal band was extracted from the frequency domain and brought back to time domain to be autocorrelated with the transmitted LFM to identify and mark the beginning of the received LFMs to allow individual extraction of TL (Fig. 15).

After LFM separation, we used Hilbert transform envelope to obtain the correct voltages amplitude on the LFM signal for each desire frequency (Fig. 16). From all 5 do $10 \mathrm{kHz}$ band we chose round frequencies of 5, 5.5, 6.0 ...9.5 and $10 \mathrm{kHz}$ to compare field results with synthetic ones to provide a measurement model's fitness to real measurements.

To compute Transmission Loss, we used the well-known relation stated in Eq.(9) (Souza, 1997):

$$
\begin{aligned}
T L & =20 \log \left(\frac{V_{T X}}{V_{R X}}\right)+T V R_{\text {Source }}+ \\
& +O C R R_{\text {Hydrophone }} d B \text { re } \mu P a @ 1 m
\end{aligned}
$$

where $V_{T X}$ is the transmission source applied voltage in Volts $(\mathrm{V}), V_{R X}$ is the receiving hydrophone delivered voltage in Volts (V), TVR is the Transmission Voltage Response in $d B$ ref $\mu P a / V @ 1 m$ and $O C R R$ is the Open Circuit Receiving Response in $d B$ re $1 \mathrm{~V} / \mu \mathrm{Pa} @ 1 \mathrm{~m}$. Figure 17 presents all receiving LFMs in frequencies from 5 to $10 \mathrm{kHz}$ in 100 $\mathrm{Hz}$ interval computed from all CHIRPS received during 320s of receiving data. Red line indicates the mean from all values from all LFM transmitted. All these values are the base for model results comparisons. 


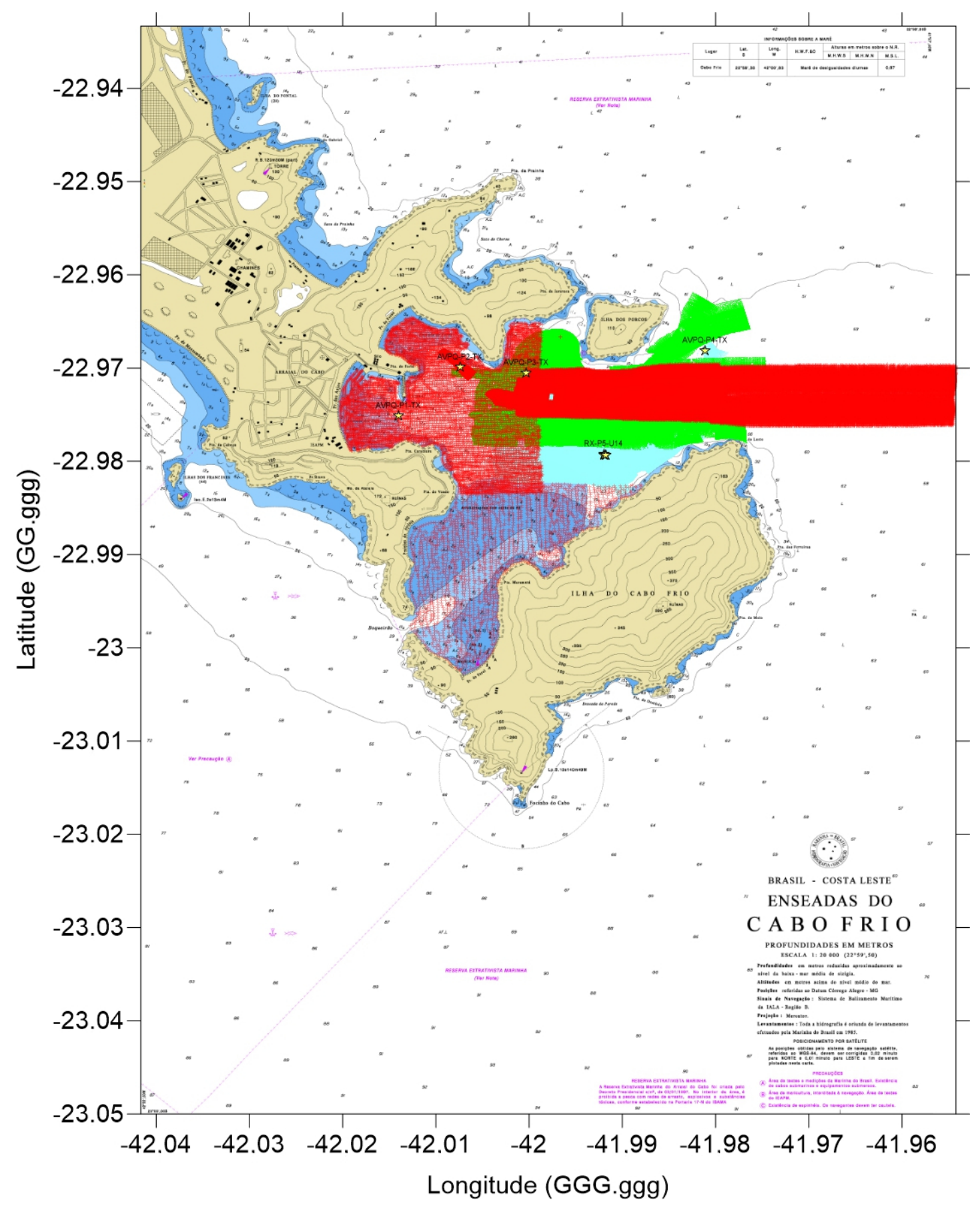

Figure 14 - All hydrographic surveys used to generate bathymetric profiles between TX and RX nodes. 

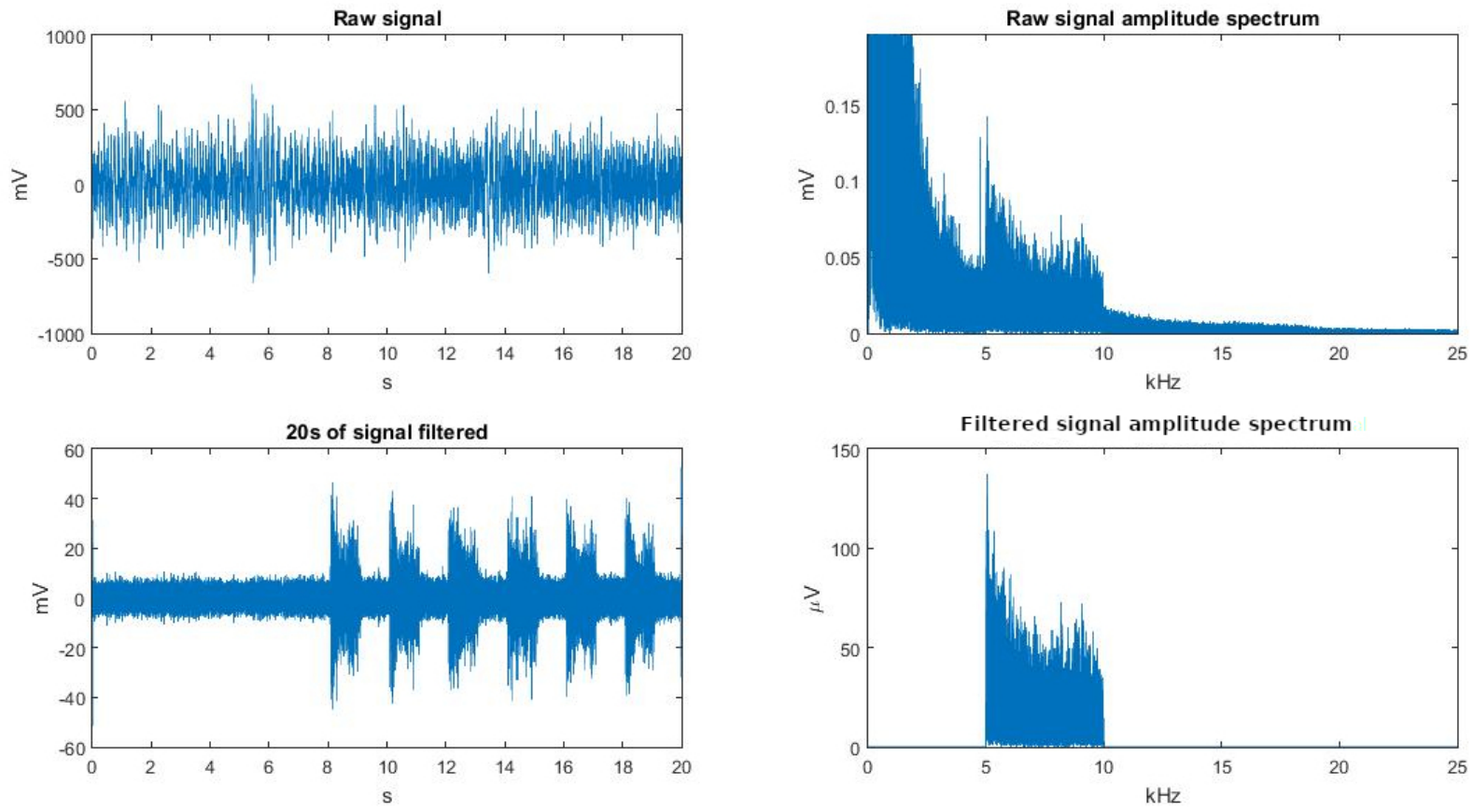

Figure 15 - CHIRP Signal Extracted from RESON TC4032.

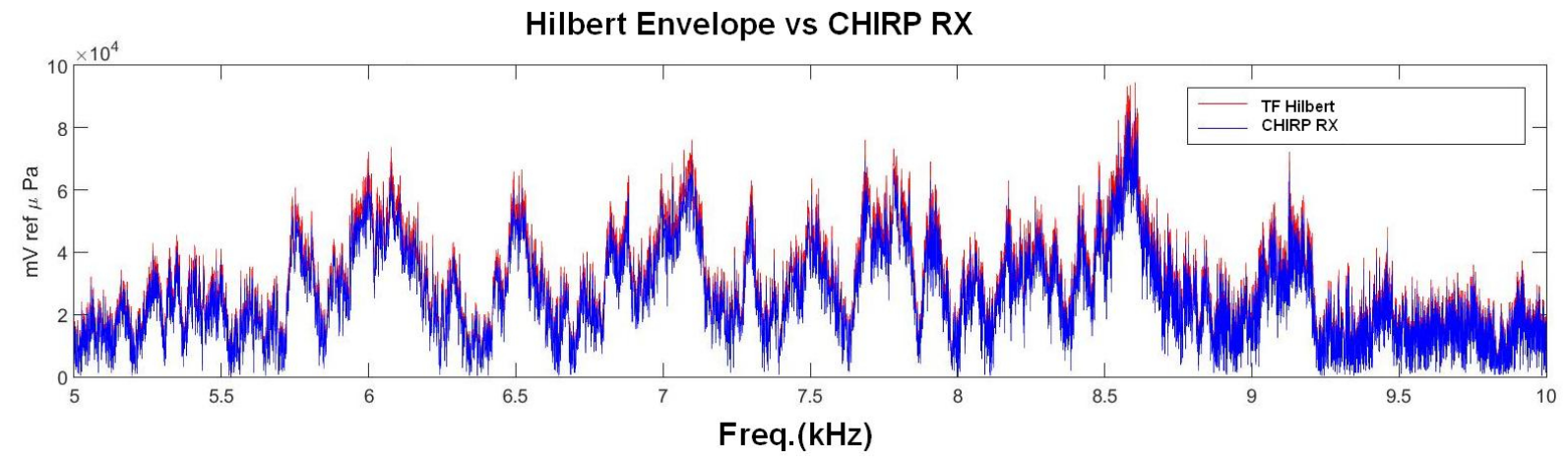

Figure 16 - TF Hilbert applied on a CHRIP Signal Extracted from RESON TC4032.

\section{Computing Synthetic Data}

Results of transmission loss were generated by Eq.(8) for three distinct bearings (P1-P5, P2-P5 and P4-P5) in different frequencies $(5,7.5$ and $10 \mathrm{kHz})$ using the final depth of the mixture layer at $12 \mathrm{~m}$ (collected in situ) and with source placed in two different positions: at $10 \mathrm{~m}$ depth (inside the mixture layer duct) and at half-way of thermocline waveguide (ideal position). Figures 18 to 21 are showing the model results.

\section{RESULTS}

Synthetic results on Figure 22 are inside the range of spherical and cylindrical ideal spreading values as in Frisk (1994); Medwin \& Clay (1998); Brekhovskikh \& Lysanov (2003); Jensen et al. (2011); and with numerical results at $23 \mathrm{~m}$ with $10 \mathrm{~dB}$ different from the measured mean and values closed spherical TL. This difference should be attributed due to the leaking energy backward and sideways from the source added to the non-absorption computation in range. Likewise, Figure 17 shows some important features like: energy duct formation, shadow and bright convergent zones as well increasing dispersion as frequency increases in different headings and frequencies. This result testify 


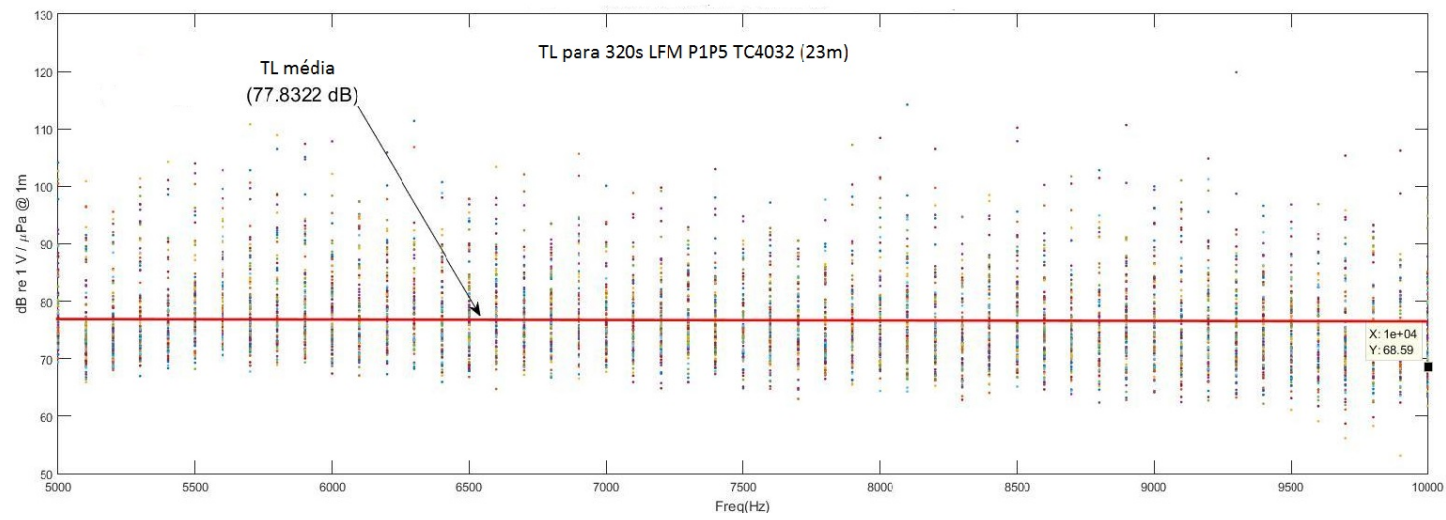

Figure 17 - TL computed at $23 \mathrm{~m}$ on RESON TC4032.

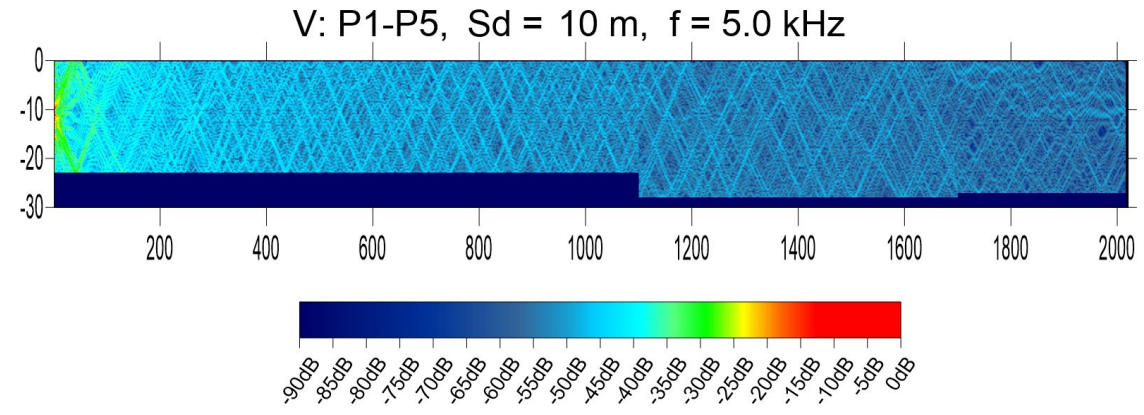

Figure 18 - TL field from P1 to P5 at $5.0 \mathrm{kHz}$, source at $10 \mathrm{~m}$ with mixture layer depth $12 \mathrm{~m}$.

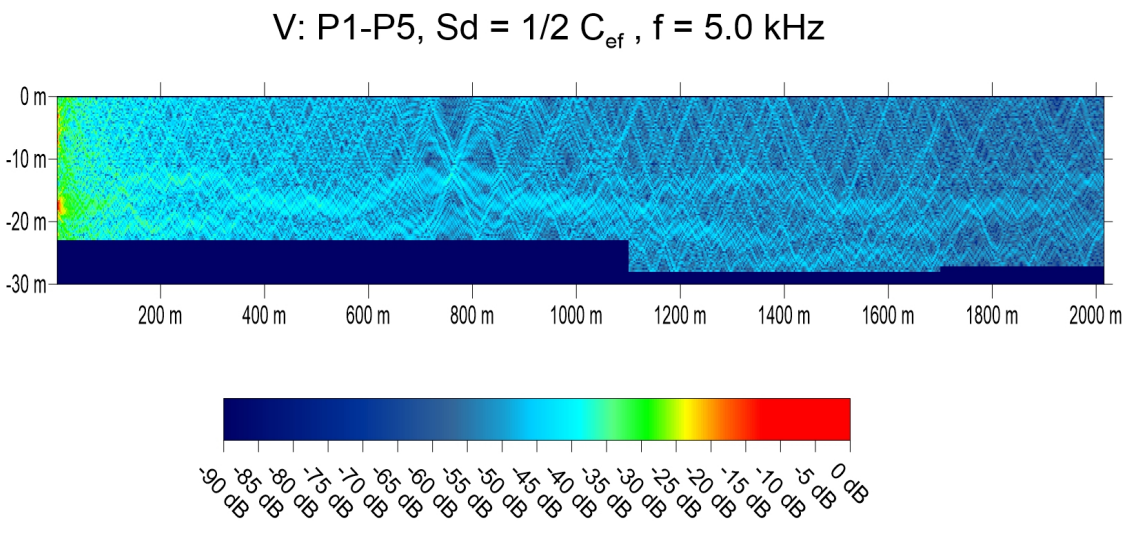

Figure 19 - TL field from P1 to P5 at $5.0 \mathrm{kHz}$, source in the middle of thermocline layer with mixture layer depth at $12 \mathrm{~m}$.

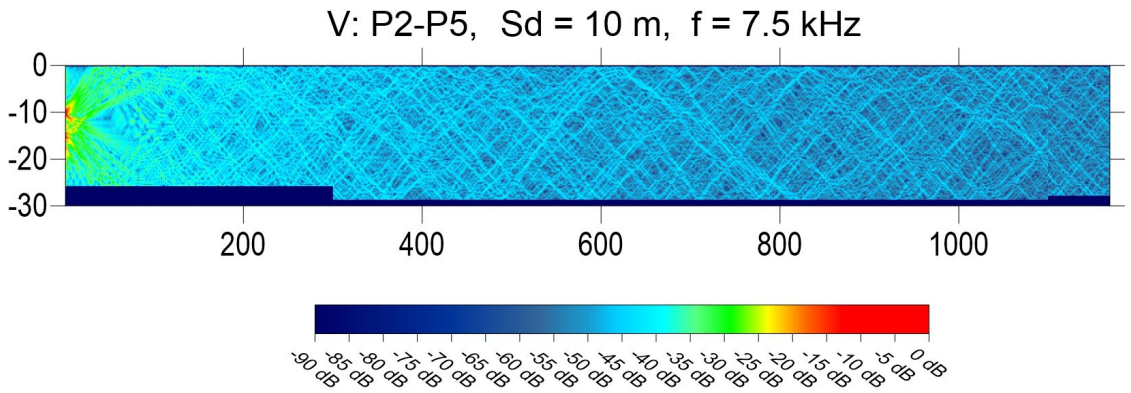

Figure 20 - TL field from P2 to P5 at $7.5 \mathrm{kHz}$, source at $10 \mathrm{~m}$ with mixture layer depth at $12 \mathrm{~m}$. 


\section{$V: P 4-P 5, S d=10 \mathrm{~m}, f=10.0 \mathrm{kHz}$}

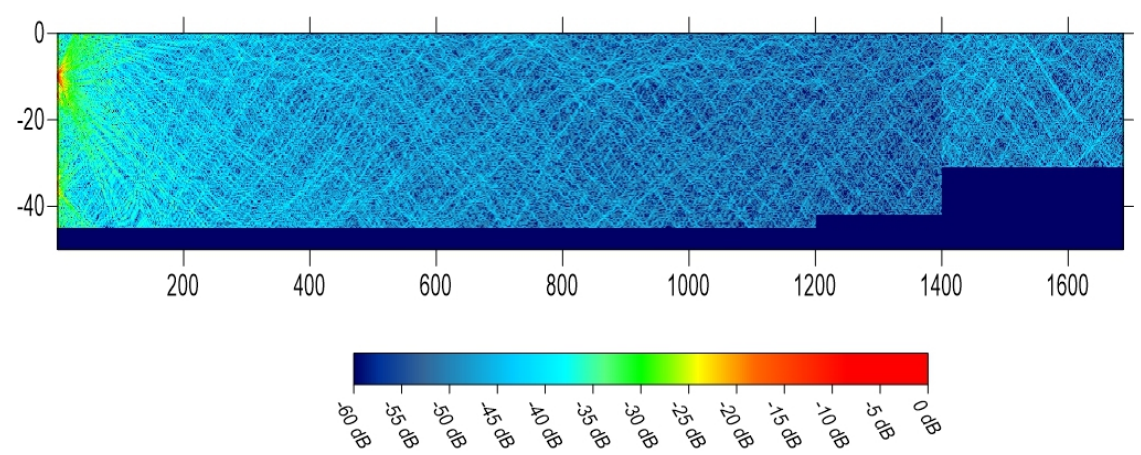

Figure 21 - TL field from P4 to P5 at $10.0 \mathrm{kHz}$, source at $10 \mathrm{~m}$ with mixture layer depth at $12 \mathrm{~m}$.
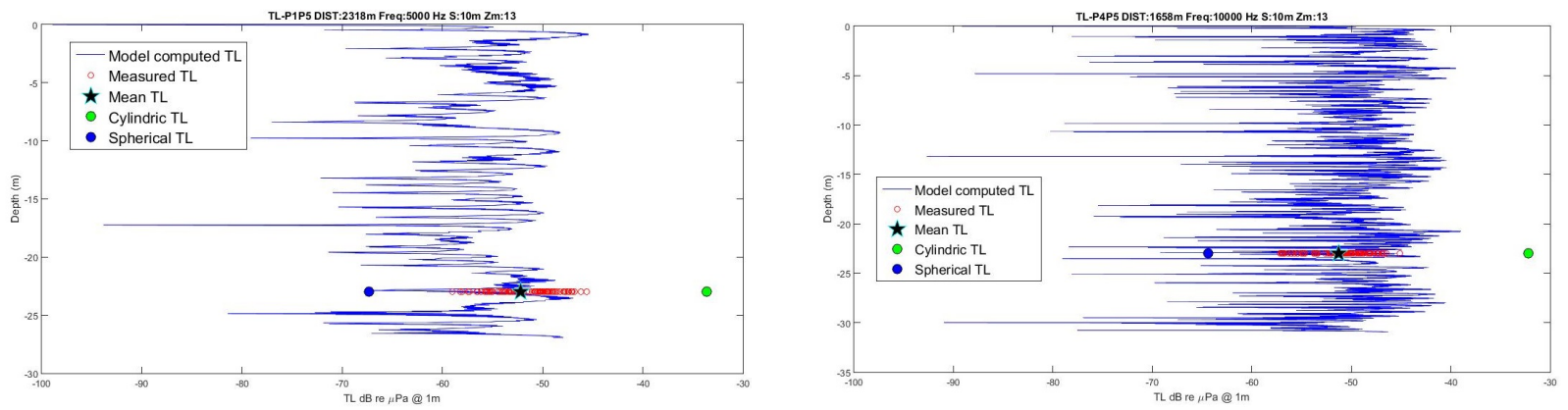

Figure 22 - TL computed at $23 \mathrm{~m}$ depth versus model results for 5 and $10 \mathrm{kHz}$ frequencies, at $2318 \mathrm{~m}$ and $1658 \mathrm{~m}$ distance from P1, with source at $10 \mathrm{~m}$ depth.

the qualitative agreement with real underwater acoustic field behavior but also impose further in situmeasurements to improve results quantitatively and qualitatively in different scenarios.

Experiment results are not showing good agreement with model results and should be repeated in the same site but in different positions to confirm not only values and signal behavior but mainly to identify the reason for a non-expected difference greater than $30 \mathrm{~dB}$ between measured and synthetic transmission loss values.

\section{CONCLUSIONS}

\section{About the model}

The presented theoretical model is to explains qualitatively the mechanism of acoustic energy transport, considering bathymetric and meteo-oceanographic variable parameters, to allow real time improvements on link performance for underwater acoustic network in shallow waters. Using the physical fundamental concepts of adiabatic resonance transmission phenomena it was possible to develop a peer to peer underwater acoustic theoretical propagation model based on modal propagation which describes satisfactorily the main flux of energy between source and receiver as showed in Figures 17 and 22. Nevertheless, the model did not respond satisfactorily not only to lateral and retroactive energy losses but also to absorption in all possible directions of propagation. Furthermore, numerical algorithms used are the most usual and tested ones allowing further researches and development on more effective and efficient numerical approaches.

\section{About the experiment}

A large amount of improvements can be done on sea experiment for in situ data collection to support model's improvements. For example, the use of divers to positioning devices (source and hydrophone arrays) in a controlled set up, include underwater attitude control instruments on hydrophone cables, install underwater current meters at all waveguide depth, set up hydrophone arrays in all waveguide depth and floating and subfloating devices to mitigate ship movement influence on hydrophone and source position. 


\section{Future work}

Theoretical approach should include lateral and backward energy leaking to mitigate the non-expected large difference between effective channel transmission loss measured from signal values and synthetic results. In situ measurements in different scenarios to stress qualitative validation and to confirm quantitatively models' results; and development of hardware and software for a real network node to install on Arraial do Cabo coves sites.

\section{ACKNOWLEDGMENTS}

The authors would like to thank the Institutions LIOC/COPPE/UFRJ (Oceanographic Instrumentation Laboratory/COPPE/UFRJ) and Underwater Acoustic Department of IEAPM/MB (Brazilian Navy Institute of Sea Research Adm. Paulo Moreira) for providing computational resources and facilities that allowed this job conclusion. To all personnel from LIOC and IEAPM Underwater Acoustics Department for the huge support on administrative tasks and in situ data collecting.

\section{REFERENCES}

BERGMANN PG. 1969. Shallow water transmission. In: Physics of Sound in the Sea, originally issued in 1948 as Division 6 Summary Technical Report of National Research Defense Committee - NDRC, Department of the Navy, Headquarters of Naval Material Command, vol. 8, 1969 reprint, 2nd ed., CRC Press, Boca Baton, Part I, chapter 6, pages $137-157$.

BREKHOVSKIKH LM. 1968. Waves in Layered Media. In: FRENKIEL FN \& TEMPLE G (Eds.). Applied Mathematics and Mechanics: An International Series of Monographs. 2nd ed., vol. 6, Academic Press Elsevier, 503 pp.

BREKHOVSKIKH LM \& LYSANOV YP. 2003. Fundamentals of Ocean Acoustics. In: FELSEN LB (Ed.). Springer Series on Wave Phenomena. 2nd ed., vol. 8, Springer-Verlag New York, Inc., 267 pp.
ELIAS LMC. 2009. Variabilidade interanual da ressurgência de Cabo Frio - RJ. Master Science Dissertation on Ocean Engineering, Postgraduate Program in Oceanic Engineering, COPPE, Universidade Federal do Rio de Janeiro, Brazil, 104 pp.

FRISK GV. 1994. Ocean and Seabed Acoustics, a theory of Wave Propagation. PTR Prentice Hall, NJ, USA, ISBN 0-13-630112-6, 291 pp.

JENSEN FB, KUPERMAN WA, PORTER MB \& SCHMIDT H. 2011. Computational Ocean Acoustics. In: AlP Series in Modern Acoustics and Signal Processing, Springer Science+Business Media, 2nd ed., LLC, New York, NY, USA, 783 pp.

MEDWIN H \& CLAY CS. 1998. Fundamentals of Acoustical Oceanography. In: STERN R \& LEVY M (Eds.). Applications of Modern Acoustics Series. Academic Press, San Diego, CA, USA, 708 pp.

PEKERIS CL, WORZEL JL \& EWING M. 1948. Propagation of Sound in the Ocean. Geological Society of America Memoir, vol. 27, Chapter: Theory of Propagation of Explosive Sound in Shallow Water, 1-116.

SILVA AC da. 2009. Dinâmica Batimétrica e Sedimentólogica da Região do Cabo Frio - Rio de Janeiro. PhD Thesis on Geology, Postgraduate program in Geology, Geoscience Institute of Universidade Federal do Rio de Janeiro, Brazil, 178 pp.

SOUZA LA de. 1997. Princípios de SONAR. Instituto de Pesquisas da Marinha - IPgM, Ilha do Governador, Rio de Janeiro, Brazil, IPqM-013-0177-ET/97, 248 pp.

TORRES JUNIOR AR. 1995. Resposta da Ressurgência Costeira de Cabo Frio a Forçantes Locais. Master Dissertation on Ocean Engineering, Programa de Pós-graduação em Engenharia Oceânica, COPPE, Universidade Federal do Rio de Janeiro, Brazil. 132 pp.

URICK RJ. 1983. Principles of Underwater Sound. 3rd ed., McGraw-Hill Book Company, USA, 423 pp.

WILSON WD. 1960. Equation for the Speed of Sound in Sea Water. The Journal of the Acoustical Society of America, 32(10): 1357. 